\title{
Global learning: A catalyst for curriculum change
}

\author{
Stephen Scoffham* - Canterbury Christ Church University, UK
}

\begin{abstract}
This article considers some of the key challenges and opportunities for global learning. It is argued that global learning is a confused terrain that is emotionally 'hot' because it impacts on deep-rooted notions of nationality and personal identity. The difficulty of engaging with controversial issues such as power relations, social injustice, migration and global poverty are explored, along with the legacy of colonialism. Recognizing that global learning aims to develop new ways of thinking suggests that progression and assessment may need to be reframed around overarching concepts and the formation of values, rather than measurable outcomes. Intriguingly, this also offers an opportunity to realign the curriculum to better address twenty-first-century needs, particularly with respect to sustainability and the environment.
\end{abstract}

Keywords: assessment; emotion; environment; post-colonial; sustainability; values

\section{Introduction}

Global learning is an evolving and contested area of the curriculum that presents teachers with considerable challenges but also great opportunities. Its roots can be traced to the immediate aftermath of the Second World War and the political process of decolonization when the development education movement first began to emerge. From these early beginnings, a range of subsequent educational initiatives such as human rights education, citizenship education, futures education and world studies took shape (Hicks, 2007). Cumulatively, these had the effect of reinvigorating the curriculum with an international perspective and inspiring teachers by introducing questions about equity and social justice into classroom discourse. Since around the turn of the twenty-first century, the term 'global' has tended to replace, or be incorporated in these earlier adjectival titles and today notions of global citizenship and global learning have widespread currency in educational circles (Bourn, 2014). Meanwhile, at a policy level, the United Nations Sustainable Development Goals (or 'Global Goals', as they are also called) have established a framework for international action across all sections of society.

What has driven this shift towards global citizenship and global learning? It is often suggested that the reason why students need to learn about the wider world is so that they can take their place in a globalized world, as Alexander (2010) reports. While this argument certainly has the appeal of relevance, it needs to be approached with caution as it tends to suggest that education is about training students to take their place in a consumer society and promulgating the values of consumerism. Huckle (2017) is well aware that educational agendas can be hijacked and points out how government support for global learning could be seen as a deliberate ploy to depoliticize movements that had hitherto been critical of the status quo. There are, 
however, more positive interpretations. Global learning, along with other aspects of humanities education, has a key role in helping students to understand themselves and others in relation to place, time, belief, identity and culture. This means it contributes to those curriculum endeavours that seek to create 'adventures in human self-understanding' (Oakeshott, 1989: 27) and that invite children to participate in their society as active and engaged citizens who are capable of dealing with complexity (Eaude, 2017). Such qualities are urgently needed. As humanity makes ever-increasing demands on the planet, eco-literacy and sustainability awareness are at a premium.

In this article, the term 'global learning' is used pragmatically to refer to a broad spectrum of initiatives that help students to understand the wider world and the environment that supports them. Crucially, these all involve recognizing connections and relationships, and the impact they have on self-awareness and identity. Thus, global learning has both objective and subjective dimensions. While there are advantages in adopting such a wide definition, there is also a danger that it could lead to ambiguity and confusion. Jorgenson (2010), for example, points out that contested terms such as 'global learning' can end up becoming little more than 'containers' to represent all manner of different policies and practices. However, new ways of thinking that cut across established subject boundaries are often beset by problems of interpretation. Acknowledging that global learning is an emerging area of study, in which terminology is evolving, makes it easier to avoid misunderstandings.

This article is written from a Western perspective and focuses especially on UK schools and primary school practice. Global learning throws the historical relations between the UK and other parts of the world into sharp relief. It also raises issues to do with power, equity and social justice, and the way that they operate in the contemporary world. Recognizing that geographical and historical positioning impacts on how global learning is understood and implemented in schools is part of coming to terms with the complexities that it conceals.

In exploring future challenges and opportunities for global learning, five main issues are considered:

(1) knowledge and understanding

(2) identity and self-image

(3) colonial legacies, stereotypes and hidden meanings

(4) pedagogy

(5) progression and assessment.

Focusing on these issues illuminates how global learning is forging new approaches to education that are in line with contemporary needs. It is argued that, as a consequence, global learning has the potential to act as a catalyst for curriculum change in the years to come.

\section{Knowledge and understanding}

For teachers, just as for policymakers, it is important to establish what constitutes knowledge and understanding in global learning, as this helps to anchor it to secure foundations. Here, the cognitive taxonomy originally devised by Bloom in 1956 still provides a useful starting point. Bloom proposed a sequence that started with lowerorder skills such as remembering and identifying facts. He suggested a second level that involved description and comprehension, while the ability to use and apply new information appeared on the third level. Bloom placed higher-order skills such 
as analysis and evaluation towards the top of the hierarchy and located original and creative thinking at its apex.

There are similarities between Bloom's taxonomy and the idea of learning spaces proposed by Andreotti (2010), based on her interpretation of post-colonial theory. In Andreotti's model, learners move from an initial position of absolute certainty to more mature understandings in which they recognize contradictions, acknowledge the validity of different perspectives and embrace complexity. In the highest levels of analysis, meaning is negotiated in conjunction with others and is regarded as provisional rather than fixed.

The broad sequence in which learners proceed from inert factual knowledge to dynamic understanding and critical awareness represents a framework for understanding progression (Scoffham, 2011). With respect to global learning, three main levels of classroom practice are particularly relevant:

(1) Information: this level involves naming and identifying different countries and finding out about the landscape and different people who live there. As such, it is centrally concerned with introducing basic vocabulary and establishing foundations for further learning.

(2) Knowledge: this level involves recognizing global links and connections between places and different groups of people. It emphasizes description and explanation and introduces questions about international relations and the way they work in practice.

(3) Understanding: this level seeks to interpret and apply knowledge about the wider world. At its best, it takes a critical stance by considering alternative structures and the values and beliefs that underpin them. It also raises questions about identity and belonging.

Making a distinction between information, knowledge and understanding is useful on a theoretical level but can be difficult to sustain in practice, as the categories merge and overlap. Furthermore, while cognitive learning is fundamental to education, affective responses also need to be taken into account. Finding out about the wider world (decentring) helps students to understand themselves in new ways as part of the global community but it serves to disrupt their existing notions, which can be a disturbing process. Emotions are also important when it comes to assessing the value of new information and prioritizing different courses of action. For example, empirical investigations by Immordino-Yang and Damasio (2007) have established how all learning involves an emotional component and that affective responses are the key to understanding what motivates students and their desire to learn. Furthermore, it should be noted that powerful emotional experiences appear to have the potential to stimulate the formation of deeply held values, as Manni et al. (2017) report.

Recognizing that global learning involves both cognitive and affective dimensions helps to illuminate the challenges that teachers have to negotiate. They need to be both well informed about global issues and have the pedagogical skills to teach students about them. In addition, global learning focuses on themes in which links and connections play out in unexpected ways. Rather than a linear sequence of cause and effect, many global issues are better viewed in terms of networks or webs. Such issues are often described as 'wicked' because they are continually evolving and can never be resolved (Bottery, 2016). They are also inherently unstable - partly because the very process of engaging with them changes their dynamics. Ambiguity and uncertainty can be deeply troubling processes and can provoke anxieties in learners. Part of the skill of the teacher is to tempt students to abandon their existing ideas and to take the 
risk of engaging with new ways of thinking. They are more likely to do this if they find themselves in a secure environment where they feel they have the necessary social and psychological support. Barnes (2018) sets out a compelling vision of what this might mean in practice.

A further consideration is that knowledge and feelings are not always directly linked. For example, a number of studies have found that when children simply learn about other countries, it does not necessarily change their attitude towards the people who live there (Bourchier et al., 2002; Reynolds and Vinterek, 2016). Young children especially appear to express preferences for particular national groups even when they have little or no factual knowledge about them (Barrett, 2007). Expanding students' perspectives is crucial for teachers of younger children, as stereotypes tend to become embedded as children grow older and, once established, are difficult to dislodge (Rowley et al., 2007).

\section{Identity and self-image}

Global learning also raises questions about identity and self-image. Research indicates that most students express a preference for their own country and tend to believe that their way of doing things is right or best (Picton, 2008). From a sociological point of view, this can be seen as an example of in-group bias. As children find out about other ways of life around the world, it provides them with different reference points and impacts on their self-understanding. How this 'mirror effect' plays out in practice varies enormously according to individual children's experiences and dispositions, but it indicates that even factual learning about the wider world can involve (and perhaps disrupt) much deeper psychological structures.

National identity is only one of many personal and social identities that students may hold, but it happens to be one that is particularly highly charged emotionally. Around the world, children are encouraged to develop a sense of loyalty to their homeland and many schools begin the day with some kind of oath or public affirmation of their statehood. At a cultural level too, young people are introduced to the literature, art, music and other achievements that define their country. As Stibbe (2015) points out, stories, myths and narratives permeate our lives and guide our actions at a deep level. Even more fundamentally, the bonds that are generated by a common language serve to tie national communities together (Galbraith, 1941). It follows that the hidden meanings, associations and collective memories that pervade learning about nations and national groups exert a powerful, if unacknowledged, influence on children and adults alike.

One area of international relations that is especially emotive concerns migration and refugees. In recentyears, the arrival of large numbers of desperate and dispossessed people from the war zones of the Middle East and Africa has provoked a political crisis in Western Europe, even though most of those who have been displaced stay in neighbouring countries (UNHCR, 2018). Humanitarian and xenophobic responses have jostled together in a confused and sometimes alarming array. Some people fear the influx of large numbers of foreigners and worry that it could undermine their prosperity and way of life. Others welcome the diversity and energy that immigration can bring (Geddes and Sholten, 2016). The way that these events have galvanized opinion illustrates how fiercely people guard their heritage when they feel their identity is threatened. Over the years, the history curriculum has excited debate and discussion in countries around the world and as Greenwood et al. (2017) report from Northern Ireland, different groups sometimes vie with each other to tell their story of the past. 
Global learning has the potential to excite equally strong, or even stronger passions. Viewing these processes from the perspective of developmental psychology, Barrett (2007) concludes that thinking in societal domains belongs to a category of its own because it is emotionally 'hot' and he argues that there is a need to understand more about how national attachments, prejudices and hostilities develop.

\section{Colonial legacies, stereotypes and hidden meanings}

If global learning is emotionally charged, it is also imbued with hidden meanings. Post-colonial theory explains how the historical relationship between the industrialized West and the Global South (developing world), which led to the creation of colonial empires, still influences contemporary understandings. It is argued that many of the countries that achieved political independence in the middle decades of the twentieth century are still dominated by the West and have yet to gain control of their economic affairs. Furthermore, the legacy of colonialism remains entrenched in their educational, judicial and governmental systems. Sharp (2009), for example, points out how Western values were insinuated into the institutions of colonized countries at the time they were subjugated. Over a period of time these values have gradually become so internalized that they are no longer consciously acknowledged, even by those who hold them. As a result, cultural decolonization (or decolonization of the mind) is much harder to achieve than statehood. It takes many decades for a nation to rediscover its authentic 'voice', particularly when confronting contrary forces associated with globalization and neo-liberalism.

Stereotypes add a further complication. In essence, stereotypes are generalized and rigid beliefs that help to organize our thinking. They can be either positive or negative, but in either event they tend to be oversimplified and hence misleading. With respect to colonialism, Said (1985) points out how Western notions of cultural superiority and the mission to 'civilize' primitive and backward people were used to justify overseas adventures and conquests. These crude stereotypes, while more muted now, still persist in the way that people in Western industrialized nations tend to use themselves as the frame of reference in international affairs and think that they need to 'help' poorer countries (to become more like themselves) economically. Overseas aid programmes and development initiatives are often justified on these grounds. Critics such as Martin and Griffiths (2014) contend that such thinking is deeply flawed, not least because it represents a 'single story' of modernity (Adichie, 2009).

Seemingly well-intentioned charitable activities can also be problematic. Referring to practices within the UK, Borowski (2011) expresses concerns that Red Nose Day and other similar campaigns that focus on compassion for those less fortunate than ourselves tend to promote distorted and undifferentiated images of the Global South. When such fundraising activities are the only sources of information available to students, they can easily be counterproductive and reinforce negative stereotypes. For example, a report by Oberman et al. (2014) into global justice found that as a result of emergency appeals, many 9-year-old Irish children tended to think that all African countries were universally poor. Griffiths and Allbut (2011) note similar misconceptions and observe that the West will always appear superior when relationships with the Global South are represented in purely economic terms.

Post-colonial theory has a number of limitations and drawbacks. To begin with, it is sometimes accused of tapping into a particular ideology and being party political. It is also criticized for presenting a very generalized and broad-brush approach that suggests an unrealistically high level of cultural homogeneity and leaves little room 
for sub-groups and differences (Moore-Gilbert, 1997). Furthermore, there is a risk that a focus on the differences between the industrialized West and the Global South will reinforce binary perspectives and encourage feelings of guilt that are liable to be counterproductive in educational terms. However, as Sund (2016) points out, postcolonial theory draws attention to principles of intra-generational equity and justice, which introduces an ethical dimension to global learning. This is integral to a deeper and critical understanding of international relations based on principles of mutuality and respect.

\section{Pedagogy}

So how can teachers negotiate the ambiguities in global learning, acknowledge the role of emotions and circumnavigate the legacy of colonialism? To begin with, there is a presumption in favour of interactive and participatory pedagogies that motivate students to investigate issues and seek answers to questions that they themselves have generated. Case studies and examples that portray actual events are also advocated, as they have immediacy and relevance and help to challenge stereotypes. These approaches are responsive to students' needs and interests, recognize that global learning is problematic and creates space for multiple perspectives. They also steer away from knowledge transmission and the risk of presenting sanitized and neatly packaged information that overlooks diversity and unwittingly reinforces a particular world view.

The way that learners approach global learning makes a considerable difference to what they learn. Andreotti (2013) offers the metaphor of travel to illustrate different approaches. She contrasts the homeowner who lives in a fenced house with the caravanner who is prepared to travel as long as they take their home with them and the camper who steps outside their comfort zone. The person who is most open to experience is the backpacker, who is subject to all manner of experiences and is willing to accept uncertainties. This metaphor makes the point that global learning is a mindset or way of thinking and that it involves a learning journey. It also chimes with transformational learning theory (Mezirow, 1997), which focuses on the mental structures that need to be dismantled if people are to see the world from inclusive, discriminating and integrating perspectives. One of the key points about transformative learning is that constructing new ways of seeing the world is an irreversible process. Once our views have been changed - Mezirow (2009: 22) calls them 'frames of reference' - we are unable to return to our earlier way of thinking. From this perspective, global learning becomes a life-changing endeavour.

One key pedagogical challenge is to find ways of moving beyond surface-level interpretations to deeper levels of understanding that question existing assumptions. Disney (2004) recognizes this in her detailed study of a linking project between schools in the UK and Goa (India), which traced the impact of the partnership on 9- to 11-yearolds over a period of several years. Not only does she express worries that the link was skewed towards UK perspectives and thus might represent a new form of colonialism, she also notes that presenting UK children with images of poverty set up a binary relationship that emphasized Western affluence and established a yardstick by which material wealth became a measure of value and worth. She argues for a more in-depth approach that considers the causes of poverty and explores the historical circumstances that have brought it about. Disney (2004: 145) concludes, 'issues of social justice are never far from the surface in projects which link UK schools with those in the poorer countries of the South' and it is important that they are addressed. 
Similar arguments apply to one-off cultural events. Listening to a band from Kenya performing traditional or improvised music, for example, is often a memorable and enjoyable experience for children in the UK. However, it presents students with an image of Kenya that is steeped in stereotypes and exoticism. It is important to consider what messages they are liable to take from this experience. Considering what Kenyan children might learn about contemporary England from watching a group of Morris dancers is one way to open up a discussion. If this were their only source of information, then it is easy to see how limited and distorted their image would be.

There is a danger that existing curricula and practices will perpetuate rather than dismantle stereotypes. Martin (2012) argues that if global learning is to avoid repeating the patterns of thought that underpinned colonialism, then it needs to be based on an ethical approach in which difference is seen as a starting point for new understanding and dialogue. Rather than learning about the world with an imperial gaze, the aim should be to develop relationships that are free from notions of cultural superiority and that recognize the bias entailed by our geographical, historical and social positioning. Only then, Martin (2012: 122) argues, 'can we start to listen to others and adopt new ways of thinking and being in the world'.

An essential part of the process of global learning, then, is to challenge children's preconceptions and prejudices and to help them think relationally. Students need enough information to appreciate the complexity and diversity of different places, but not so much that they become swamped with detail. Taylor (2011) argues for a balanced approach and advises teachers to find points that are appropriate for different classes and individuals on what she calls the 'complexity-accessibility continuum'. This strategy holds out the promise of undermining stereotypes by introducing students to multiple rather than single stories without asking them to assimilate more information than they are able to handle.

\section{Progression and assessment}

Being able to establish that learning has occurred is essential in any educational endeavour. It is a particular challenge in evolving areas of the curriculum such as global learning where the frames of reference and modes of thought have yet to be fully established. It was claimed earlier that global learning suffers from being ill-defined and ambiguous. This lack of clarity inevitably impacts on notions of achievement. In these circumstances, it is more realistic to look for indicators that will act as signposts of progress, rather than for precise and quantifiable measures. It follows that the professional wisdom and judgement of teachers is liable to be particularly important when it comes to assessing student progress.

Notions of progression are intimately linked with ideas about child development and extend far beyond the confines of an individual classroom. This was one of the factors that led Owens and Hopkin (2015) to argue for a whole-school approach that addresses institutional ethos as well as more specific learning objectives. The wholeschool expectations that Owens and Hopkin suggest identify qualitatively different outcomes for children of different ages. At Key Stage 1 (ages 5-7), there is an emphasis on the way that children connect to different places and their sense of themselves in the wider world. Indirect knowledge of diverse people, places and environments and world place knowledge are featured in Key Stage 2 (ages 7-11). At Key Stage 3 (ages 11-14), concepts such as development, globalization, interdependence and sustainability are highlighted. Although these expectations are necessarily lacking in 
detail, they begin to provide a route map that is aligned to children's development and pointers as to what it might mean to be globally literate.

There are also a number of theoretical models that help to illuminate progression in global learning in different ways. For example, Schmeinck (2009) sets out a model of progression, derived from earlier ideas proposed by Bruner, in which children gain increasing knowledge and competence as they progress up an ever-widening spiral of experience and understanding. Schmeinck (2009: 92) identifies four separate but complementary strands that, although focused on spatial awareness, are equally applicable to global learning. These are: (1) areas that children experience directly; (2) places they are acquainted with; (3) imagined areas; and (4) foreign areas. The model suggests that all four strands are present as children move through different levels of development, but that they need to be approached in different ways according to the age and ability of the students. It also emphasizes the importance of revisiting themes and topics, thereby qualifying more simplistic ideas about linear progress and development. The implication is that global learning is appropriate for children of all ages, even the very young. This seems entirely appropriate given the fact that children will be aware of the wider world and have started to form ideas, however embryonic, about places beyond their direct experience even before they come to school (Catling, 2015).

To make better sense of progression and assessment in global learning, we need to ask a simple but fundamental question: what is global learning for? If it is essentially seen as developing cartographic knowledge and factual understanding, then memorizing information will be a high priority. If it is regarded as supporting globalization and enabling students to take their place in the world more effectively, then global learning will need to focus on economic relationships and power structures. However, neither of these approaches is likely to challenge the assumptions that children will have already developed about the wider world, their place within it and how they relate to themselves and others.

A focus on critical understanding implies a very different notion of progression in global learning. As Blackmore (2016) points out, developing the work of Burbules and Beck (1999), it involves thinking differently and encouraging learners to see their actions in context. This is an unpredictable process that is hard to assess and that cannot easily be reduced to the kind of competencies now favoured by accountability cultures in many parts of the world (Cremin, 2017). From this perspective, students' willingness to engage needs to be considered along with their progress towards predetermined outcomes. They will exhibit their ability in the way they deconstruct representations of people and places and recognize the implications of different courses of action. Understanding concepts, recognizing complexity and imagining possibilities become key considerations. It takes time to develop these kinds of learning because they are, as Eaude (2017: 348) puts it, 'sinuous processes' that cannot be neatly pinned down.

Finally, global learning inevitably brings students into contact, either directly or indirectly, with their counterparts in other countries. This raises profound moral questions about how these encounters are negotiated. Andreotti (2010), Martin (2011) and Bourn et al. (2016) all argue strongly for an ethical engagement with other people and cultures and there is a good case for factoring values formation into any progression framework. There is also a raft of questions about how people relate to the natural world and whether they see they themselves as bound by the processes of nature or in a stewardship role. This aspect of global learning is one of its most salient features because developing environmental consciousness and a sustainability 
mindset are liable to be a key quality in the 'troubled times' (Hicks, 2014: 173) that lie ahead.

\section{Conclusion}

Embarking on global learning means entering a contested and confusing terrain. Teachers need considerable skill to negotiate the historical baggage of colonialism. They have to be particularly adroit when it comes to exploring contemporary issues such as unequal power relations, social injustice, migration and global poverty. This draws attention to neo-liberal ideologies that currently dominate thinking in the Western industrialized world. These ways of thinking are often so deeply embedded that they may not even be consciously acknowledged. Uncovering the assumptions that underpin our thinking is both one of the challenges and prizes of global learning.

Global learning, then, draws teachers into reflecting on their own ideas about other peoples and cultures, being sensitive to bias and acknowledging their values and beliefs. Sometimes, even apparently innocent questions about poverty and inequality require a sophisticated and deep understanding of underlying issues, if they are to be answered honestly but simply. Furthermore, realizing on an emotional level that Western prosperity (both past and present) is predicated on exploitation and violence - the dark side of capitalism - is no easy matter and can trigger what Lisa Taylor has called 'epistemic vertigo' (Andreotti et al., 2010: 13). There are those, like Furedi (2009), who are critical of global learning because they fear it might be viewed as a policy instrument for solving society's ills. Others express concerns that global learning focuses on 'soft skills' and thus has an anti-intellectual bias (Ecclestone and Hayes, 2009: 107). Meanwhile, Standish (2012) is aware it could be harnessed to indoctrinate students into a predetermined set of values or beliefs.

These are important arguments. The general point is that education becomes tainted if it is allied to particular causes and campaigns. However, recognizing that global learning draws students into controversial issues and dilemmas is not a reason to ignore it. Quite the contrary, as a focus on uncontested facts would be both intellectually dishonest and educationally sterile. What it signals is that teachers need to encourage students to take a critical stance and question the basis for their assumptions and beliefs. Indoctrination only becomes an issue when students are steered into unquestioningly adopting a predetermined ideological position. Most teachers are wary of being 'political' (Bourn et al., 2016) and naturally shy away from issues that they know are going to be divisive in the classroom (Greenwood et al., 2017). The governance and management structures of schools, parental pressure and the demands of the curriculum act as further constraints.

As we move further into the twenty-first century, it is becoming apparent that a number of significant shifts in both teaching and learning are gathering momentum. The old idea that knowledge is certain and fixed is being replaced by an awareness that facts are provisional and that change is continual. The extraordinary development and proliferation of electronic media has undermined established academic hierarchies and ushered in a more democratic era of information exchange and communication. There is a greater emphasis on the construction of knowledge, contextual understanding and holistic perspectives. Furthermore, the scientific paradigms that have proved so effective in guiding Western thought in previous centuries are losing their power in the face of notions such as interdependence, cycles, partnership, flexibility and diversity that are drawn from ecology (Capra and Luisi, 2014). 
In classroom contexts, learning often happens within established boundaries and getting to the point where it is possible to question underlying assumptions and values is not always easy (Scoffham, 2013). Much depends on the enthusiasm and skills of the teacher and the experience and disposition of learners. Furthermore, as Bourn et al. (2016) point out, many UK primary schools have responded to the global learning and sustainability agendas by providing children with additional knowledge, rather than rethinking the purpose of education itself or developing a pedagogy that will help them to meet future environmental challenges. Despite these difficulties, there are good reasons to believe that global learning will continue to foster curriculum innovation and development. It is, as Andreotti (2013: 12) puts it, uniquely placed to expand students' world views and introduce them to 'different spaces, forms of living and ways of knowing'. This is, quite simply, one of the most significant things that teachers can achieve.

In many ways, Western education is maladapted to contemporary circumstances. In the UK, as in many other countries, schools have changed remarkably little since Victorian times and remain geared towards standardization and conformity, just as they were in the industrial era (Robinson and Aronica, 2015). Furthermore, at a time when the curriculum has become increasingly compromised by the 'standards' agenda (Alexander, 2010), it is often difficult for teachers to focus on some of the most pressing issues of the age, such as international relations, migration, global awareness and environmental sustainability. Encouragingly, there are many examples of small-scale initiatives and educational experiments that explore new approaches to education (Assadourian, 2017), but they have yet to become widespread. Global learning takes its place alongside these developments. At its most profound, it holds out the promise of a change in mindset that matches current circumstances. Seen in this light, global learning could become one of the catalysts for wider curriculum reform. This is a vision that needs to be constantly nurtured, so that it grows and flourishes in the face of contrary forces.

\section{Notes on the contributor}

Stephen Scoffham is a visiting reader in sustainability and education at Canterbury Christ Church University, where he focuses on developing sustainability perspectives in academic life. An established educational author and school atlas consultant, Stephen is the President of the Geographical Association (2018/19). His latest books include Teaching Geography Creatively (Routledge, 2017, 2nd ed.) and Leadership for Sustainability in Higher Education (Bloomsbury Academic, 2018).

\section{References}

Adichie, C.N. (2009) 'The danger of a single story'. Online. https://www.ted.com/talks/chimamanda_ adichie_the_danger_of_a_single_story/transcript (accessed 27 May 2018).

Alexander, R. (ed.) (2010) Children, Their World, Their Education: Final report and recommendations of the Cambridge Primary Review. London: Routledge.

Andreotti, V. (2010) 'Global education in the "21st century": Two different perspectives on the "post-" of postmodernism'. International Journal of Development Education and Global Learning, 2 (2), 5-22.

Andreotti, V. (2013) 'Taking minds to other places'. Primary Geography, 80 12-13.

Andreotti, V., Jefferess, D., Pashby, K., Rowe, C., Tarc, P. and Taylor, L. (2010) 'Differences and conflict in higher education in Canada'. International Journal of Development Education and Global Learning, 2 (3), 5-14. 
Assadourian, E. (2017) 'EarthEd: Rethinking education on a changing planet'. In Worldwatch Institute EarthEd: Rethinking education on a changing planet. Washington, DC: Island Press, 3-20.

Barnes, J. (2018) Applying Cross-Curricular Approaches Creatively. London: Routledge.

Barrett, M. (2007) Children's Knowledge, Beliefs and Feelings about Nations and National Groups. Hove: Psychology Press.

Blackmore, C. (2016) 'Towards a pedagogical framework for global citizenship education'. International Journal of Development Education and Global Learning, 8 (1), 39-56.

Bloom, B.S. (ed.) (1956) Taxonomy of Educational Objectives, Handbook 1: The cognitive domain. New York: Longman.

Borowski, R. (2011) 'The hidden cost of a red nose'. Primary Geography, 75, 18-20.

Bottery, M. (2016) Educational Leadership for a More Sustainable World. London: Bloomsbury Academic.

Bourchier, A., Barrett, M. and Lyons, E. (2002) 'The predictors of children's geographical knowledge of other countries'. Journal of Environmental Psychology, 22 (1-2), 79-94.

Bourn, D. (2014) The Theory and Practice of Global Learning (Development Education Research Centre Research Paper 11). London: Institute of Education.

Bourn, D., Hunt, F., Blum, N. and Lawson, H. (2016) Primary Education for Global Learning and Sustainability. York: Cambridge Primary Review Trust.

Burbules, N.C. and Beck, R. (1999) 'Critical thinking and critical pedagogy: Relations, difference and limits'. In Popkewitz, T.S. and Fendler, L. (eds) Critical Theories in Education: Changing terrains of knowledge and politics. London: Routledge, 45-66.

Capra, F. and Luisi, P.L. (2014) The Systems View of Life: A unifying vision. Cambridge: Cambridge University Press.

Catling, S. (2015) 'Giving younger children voice in primary geography: Empowering pedagogy - a personal perspective'. In Catling, S. (ed.) Research and Debate in Primary Geography. London: Routledge, 217-39.

Cremin. T. (2017) 'Series editor's foreword'. In Pickering, S. (ed.) Teaching Outdoors Creatively. London: Routledge, ix-xiii.

Disney, A. (2004) 'Children's developing images and representations of the school link environment'. In Catling, S. and Martin, F. (eds) Researching Primary Geography. London: Register of Research in Primary Geography, 139-47.

Eaude, T. (2017) 'Humanities in the primary school: Philosophical considerations'. Education 3-13: International Journal of Primary, Elementary and Early Years Education, 45 (3), 343-53.

Ecclestone, K. and Hayes, D. (2009) The Dangerous Rise of Therapeutic Education. London: Routledge.

Furedi, F. (2009) Wasted: Why education isn't educating. London: Continuum.

Galbraith, V.H. (1941) 'Nationality and language in medieval England'. Transactions of the Royal Historical Society, 23, 113-28.

Geddes, A. and Scholten, P. (2016) The Politics of Migration and Immigration in Europe. 2nd ed. London: SAGE Publications.

Greenwood, R., Richardson, N. and Gracie, A. (2017) 'Primary humanities: A perspective from Northern Ireland'. Education 3-13: International Journal of Primary, Elementary and Early Years Education, 45 (3), 309-19.

Griffiths, H. and Allbut, G. (2011) 'The danger of a single image'. Primary Geography, 75, 16-17.

Hicks, D. (2007) 'Responding to the world'. In Hicks, D. and Holden, C. (eds) Teaching the Global Dimension: Key principles and effective practice. London: Routledge, 3-13.

Hicks, D. (2014) Educating for Hope in Troubled Times: Climate change and the transition to a postcarbon future. London: Trentham Books.

Huckle, J. (2017) 'Becoming critical: A challenge for the Global Learning Programme?'. International Journal of Development Education and Global Learning, 8 (3), 63-84.

Immordino-Yang, M.H. and Damasio, A. (2007) 'We feel, therefore we learn: The relevance of affective and social neuroscience to education'. Mind, Brain, and Education, 1 (1), 3-10.

Jorgenson, S. (2010) 'De-centering and re-visioning global citizenship education abroad programs'. International Journal of Development Education and Global Learning, 3 (1), 23-38.

Manni, A., Sporre, K. and Ottander, C. (2017) 'Emotions and values: A case study of meaningmaking in ESE'. Environmental Education Research, 23 (4), 451-64.

Martin, F. (2011) 'Global ethics, sustainability and partnership'. In Butt, G. (ed.) Geography, Education and the Future. London: Continuum, 206-24.

Martin, F. (2012) 'The geographies of difference'. Geography, 97 (3), 116-22. 
Martin, F. and Griffiths, H. (2014) 'Relating to the "other": Transformative, intercultural learning in post-colonial contexts'. Compare: Journal of Comparative and International Education, 44 (6), 938-59.

Mezirow, J. (1997) 'Transformative learning: Theory to practice'. New Directions for Adult and Continuing Education, 74, 5-12.

Mezirow, J. (2009) 'Transformative learning theory'. In Mezirow, J. and Taylor, E.W. (eds) Transformative Learning in Practice: Insights from community, workplace, and higher education. San Francisco, CA: Jossey Bass, 18-32.

Moore-Gilbert, B. (1997) Postcolonial Theory: Contexts, practices, politics. London: Verso.

Oakeshott, M. (1989) 'A place of learning'. In Fuller, T. (ed.) The Voice of Liberal Learning: Michael Oakeshott on education. New Haven: Yale University Press, 17-42.

Oberman, R., O'Shea, F., Hickey, B. and Joyce, C. (2014) Children's Global Thinking: Research investigating the engagement of seven- to nine-year-old children with critical literacy and global citizenship education. Dublin: Education for a Just World.

Owens, P. and Hopkin, J. (2015) 'Progression in global learning'. Primary Geography, 87, 6-7.

Picton, O.J. (2008) 'Teaching and learning about distant places: Conceptualising diversity'. International Research in Geographical and Environmental Education, 17 (3), 227-49.

Reynolds, R. and Vinterek, M. (2016) 'Geographical locational knowledge as an indicator of children's views of the world: Research from Sweden and Australia'. International Research in Geographical and Environmental Education, 25 (1), 68-83.

Robinson, K. and Aronica, L. (2015) Creative Schools: Revolutionizing education from the ground up. London: Allen Lane.

Rowley, S.J., Kurtz-Costes, B., Mistry, R. and Feagans, L. (2007) 'Social status as a predictor of race and gender stereotypes in late childhood and early adolescence'. Social Development, $16(1), 150-68$

Said, E.W. (1985) 'Orientalism reconsidered'. Cultural Critique, 1, 89-107.

Schmeinck, D. (2009) 'Up to the garden fence or the world at primary school'. Orbis Scholae, 3 (2), 77-95.

Scoffham, S. (2011) 'Core knowledge in the revised curriculum'. Geography, 96 (3), 124-30.

Scoffham, S. (2013) '"Do we really need to know this?": The challenge of developing a global learning module for trainee teachers'. International Journal of Development Education and Global Learning, 5 (3), 28-45.

Scoffham, S. (forthcoming, 2019) 'The world in their heads: Children's ideas about other nations, peoples and cultures'. International Research in Geography and Environmental Education.

Sharp, J.P. (2009) Geographies of Postcolonialism. London: SAGE Publications.

Standish, A. (2012) The False Promise of Global Learning: Why education needs boundaries. London: Continuum.

Stibbe, A. (2015) Ecolinguistics: Language, ecology and the stories we live by. London: Routledge.

Sund, L. (2016) 'Facing global sustainability issues: Teachers' experiences of their own practices in environmental and sustainability education'. Environmental Education Research, 22 (6), 788-805.

Taylor, L. (2011) 'The negotiation of diversity'. Teaching Geography, 36 (2), 49-51.

UNHCR (United Nations High Commissioner for Refugees) (2018) 'UNHCR statistics: The world in numbers'. Online. http://popstats.unhcr.org/en/ (accessed 3 June 2018). 